\title{
A FALSA REPRESENTAÇÃO DA IDENTIDADE BRASILEIRA NA CONSTRUÇÃO DO PERSONAGEM ZÉ CARIOCA DA DISNEY
}

\section{MISREPRESENTATION OF BRAZILIAN IDENTITY IN THE CONSTRUCTION OF DISNEY'S} CHARACTER ZÉ CARIOCA

\section{LA FALSA REPRESENTACIÓN DE LA IDENTIDAD BRASILEÑA EN LA CONSTRUCCIÓN DEL PERSONAJE ZÉ CARIOCA DE DISNEY}

\footnotetext{
${ }^{1}$ Doutor em Estudos Literários. Docente do curso de Letras da Universidade Federal da Fronteira Sul - UFFS 
RESUMO: Zé Carioca estreou, a partir de 1942, dois longas-metragens e um curta de desenho animado, teve sua própria tira de jornal por dois anos e foi uma das estrelas nos quadrinhos "Ducks". No Brasil, ele foi um personagem principal em seus próprios quadrinhos, e sua fama como ícone cultural provavelmente é equivalente à de Mickey Mouse, nos EUA. Este artigo se deterá em alguns problemas na construção de Zé Carioca e na forma como ele representa (ou deturpa) traços da "identidade brasileira", já que foi criado sob fortes motivações políticas. Além disso, tentará compreender como pode esse personagem ser inscrito como uma das formas de autorrepresentação na nossa tradição cultural e como erros em sua concepçáo podem ter efeitos deletérios na formação de nossa identidade cultural, especialmente a partir da década de 1970, uma década em que as HQs da Disney gozaram de alta popularidade no Brasil.

ABTRACT: Zé Carioca, or Joe Carioca, starred in 1942 in two feature films and a short cartoon, had his own newspaper strip for two years and had a part in the "Ducks" comics. In Brazil, he was the main character in his own comics, and his fame as a cultural icon is probably equivalent to that of Mickey Mouse in the USA. This article will focus on some problems in the construction of Zé Carioca character and on how he represents (or misrepresents) traits of the "Brazilian identity", since it was created under strong political motivations. In addition, it will attempt to understand how such a character can be inscribed as one of the forms of self-representation in our cultural tradition and how errors in its conception can have had deleterious effects on the formation of our cultural identity, especially since the 1970s, a decade in which Disney comics have enjoyed high popularity in Brazil.

RESUMEN: Zé carioca protagonizó, a partir de 1942, dos largometrajes y un cortometraje de dibujos animados, tuvo su propia historieta en un periódico por dos ańos y fue una de las estrellas en los cómics "Ducks". En Brasil, fue el personaje principal en sus propios cómics y su fama como icono cultural probablemente es equivalente a la de Mickey Mouse en Estados Unidos. Este artículo se detendrá en algunos problemas en la construcción de Zé Carioca y en la forma como él representa (o falsea) rasgos de la "identidad brasileña", puesto que fue creado bajo fuertes motivaciones políticas. Además, intentaremos comprender cómo puede haber sido considerado como una de las formas de autorrepresentación en nuestra tradición cultural y como errores en la concepción del personaje pueden tener efectos deletéreos en la formación de nuestra identidad cultural, especialmente a partir de la década de 1970, una década en que los cómics de Disney gozaron de alta popularidad en Brasil.

PALAVRAS-CHAVE: Histórias em quadrinhos; Zé Carioca; Malandragem; Identidade Nacional.

IKEYWORDS: Comic books; Zé Carioca; Malandragem; National Identity.

PALA VRAS CLAVE: Cómics; Zé Carioca; Malandragem; Identidad Nacional. 
Em primeiro lugar, é importante reconhecer o trabalho de crítica de história em quadrinhos How to read Donald Duck, escrito pelos chilenos Ariel Dorfman e Armand Mattelard, em 1971, em meio ao processo revolucionário pelo qual passava o Chile. Seu trabalho removeu a máscara de inocência que, por muito tempo, escamoteou a face real de um plano para espalhar a ideologia capitalista e revelou mecanismos de colonizaçáo psicológica e cultural que poderiam deixar a propaganda nazista com inveja. É preciso também reconhecer que o objetivo principal na guerra imperialista tem sido conquistar mais por meio de infiltração ideológica do que por armas, embora estas últimas tenham sido usadas sem parcimônia sempre que tenha sido conveniente. No primeiro caso, que envolve mais sutileza, Hollywood e Disney fizeram um excelente trabalho, especialmente na América Latina.

Essa influência da indústria cultural americana nos países latino-americanos foi consolidada no período pós-guerra. Se considerarmos que a Segunda Guerra Mundial foi principalmente uma disputa expansionista por novos mercados e que alguns países da América do Sul estavam naquele momento flertando com a Alemanha de Hitler, especialmente a Argentina e o Brasil, que experimentavam governos autoritários sob o comando de Juan Perón e Getúlio Vargas, foi então o momento certo para um movimento ofensivo da indústria cultural americana nesses países.

Em 1941, quando o governo dos EUA estava tentando uma aproximação com os países latino-americanos, Nelson Rockefeller sugeriu à Disney uma visita à América do Sul. Para criar algum vínculo como sinal de simpatia e amizade entre os EUA e os países latinoamericanos, a Disney criou três personagens representando o continente americano: Donald Duck, um mariner norte-americano; Panchito, representando o México e os outros países hispânicos, e Zé (Joe) Carioca, o personagem brasileiro. Ao criar o personagem Zé carioca, valeram-se de traços estereotipados, que não refletem as ambiguidades da personalidade histórica do malandro.

Este artigo se deterá em alguns problemas na construção de Zé Carioca e na forma como ele representa erroneamente (ou deturpa) o "caráter brasileiro", já que foi criado sob 
fortes motivaçôes políticas. Além disso, tentará compreender como pode esse personagem ser inscrito como uma das formas de autorrepresentação na nossa tradição cultural e como erros em sua concepção podem ter tido efeitos deletérios na formação de nossa identidade cultural, especialmente a partir da década de 1970, uma década em que as HQs da Disney gozaram de alta popularidade no Brasil.

Antes de iniciar a discussão, é importante deixar claro o pressuposto de que se refuta a ideia de uma identidade nacional única, especialmente num país de dimensôes continentais como o Brasil, marcado por inúmeras diferenças regionais, sociais e culturais. Reconhecemos, no entanto, que houve na história do país uma enorme ansiedade e um esforço teórico na tentativa de definir a nossa "brasilidade" em termos, às vezes, bastante essencializantes, principalmente em momentos de exaltação ufanista do nacionalismo, como foram os períodos da Era Vargas e da Ditadura Militar de 1964, que serão focalizados aqui.

\section{ZÉ CARIOCA E A TRADIÇÃo DE MALANDROS DA CULTURA BRASILEIRA}

Zé Carioca estreou, a partir de 1942, dois longas-metragens e um curta de desenho animado, teve sua própria tira de jornal por dois anos e foi uma das estrelas nos quadrinhos "Ducks". No Brasil, ele foi, de fato, um personagem principal em seus próprios quadrinhos, e sua fama como ícone cultural provavelmente é equivalente à de Mickey Mouse nos EUA. Sua primeira aparição foi no filme Saludos, Amigos (Alô, amigos, no Brasil) em 1943 e, mais tarde, em The Three Caballeros (Você já foi à Bahia?), em 1944. Depois disso, uma tira de jornal americano relatou suas novas aventuras no final da década de 1940 até meados da década de 1950, mas, desde então, Zé Carioca, virtualmente, desapareceu dos Estados Unidos.

O melhor amigo de Zé Carioca é um corvo chamado Nestor, que parece ter o mesmo relacionamento que Pateta tem com Mickey (companheirismo), embora Zé tire o máximo proveito da credulidade de Nestor. Outros amigos incluem um sujeito de pele escura chamado Pedrão, e um pato chamado Afonsinho. Zé, como o Pato Donald, também tem dois sobrinhos chamados Zico e Zeca. O seu rival para as afeiçóes de Aurora, sua 
paquera, é um galo chamado Zé Galo. Outro dos seus adversários típicos é o pai de Aurora, Roca Vaz, porque ele desaprova o afeto de José por sua filha.

Zé Carioca é um papagaio antropomorfizado, retratado como preguiçoso, malandro, que gosta de enganar as pessoas, sempre se esconde de seus credores e gosta de flertar com muitas mulheres. Em suma, seria a representação falsa de um malandro. Digo falsa porque é uma representação unidimensional, que faz desses traços um atalho para essencializar uma identidade que é muito mais complexa. Fica evidente que o personagem Zé Carioca foi construído a partir de um estereótipo, aquele malandro carioca das primeiras décadas do século XX, uma figura marginal, normalmente um negro ou mestiço, avesso ao trabalho, que vivia de expedientes, cultuava a vadiagem, a capoeira e o samba.

As produçóes da Disney foram decisivas para a formação de um estereótipo que se difundiu mundo afora no período pós-segunda guerra mundial. Segundo afirma Rodrigo Cavalcante, "dali em diante, a imagem do brasileiro se firmava como a de uma espécie de bon vivant tropical, cheio de ginga, que não se adaptava a empregos formais e vivia de 'bicos”". (CAVALCANTE,2005, p.71-72). Formou-se, dessa maneira, um dos símbolos identificadores de nossa identidade nacional, tanto internamente, como no exterior. Tratase, porém, de um símbolo que não dá conta dos níveis mais complexos de nossa heterogeneidade étnico-cultural que o compóem historicamente.

A figura do malandro, construída ao longo da história, é cheia de nuances, um personagem extremamente ambíguo, cujas representaçóes na cultura brasileira retrocedem a relatos e novelas orais picarescas, como o herói popular Pedro Malazarte, da tradição oral; Leonardo, o desastroso anti-herói do sui generis romance Memórias de um Sargento de Milícia, ou Macunaíma, herói do romance modernista Macunaíma, de Mário de Andrade, que tem como subtítulo uma definição: "O herói sem nenhum caráter”.

É importante observar que os dois primeiros heróis são realmente picarescos, especialmente se concordarmos que o problema do pícaro é um "problema de hambre" como dizem os espanhóis. Pelo fato de ser pobre, sua malandragem é imposta pela necessidade, e seu cinismo moral, em vez de ser um atributo intrínseco de sua personalidade, é mais uma defesa contra o viláo dominante. Por outro lado, em 
Macunaíma, o herói sem nenhum caráter, representado como luxurioso, ocioso e sonhador, em uma síntese presumível do modo de ser brasileiro, sua malandragem e sua moral nãoconvencional são apresentadas como características intrinsecamente herdadas.

Essa última é uma concepção perigosa que foi comprada por muitos escritores brasileiros e não brasileiros e levou muitos a uma representação enganosa que se tornou, com o passar do tempo, falsa, se concebermos uma falsa representação quando motivada por interesses corporativos de um grupo em relação a outros, como parece ter ocorrido no caso da elaboração do personagem Zé Carioca.

No caso dos personagens Zé Carioca e Macunaíma, parece que seu papel é fixo e imune às influências históricas. Sua psicologia é dada a priori e não se transforma. Em ambas as narrativas o que se transforma, de maneira intensa, é o seu entorno: a paisagem, os cenários, os ambientes. Os protagonistas são imunes à mudança.

Dorfman e Mattelart observaram as mudanças sucessivas de cenário, como, por exemplo, a mudança constante nos padróes de cores, ou a obsessão pela novidade e bugigangas (gadgets) nos quadrinhos da Disney. Pareceu-lhes que a surpreendente aplicação do movimento e da inovação nas histórias funciona para criar uma ilusão de que tudo está em movimento quando na verdade nada muda: "This change of externals over identical and rigid content, the application of a fresh coat of paint from one picture to the next, is the correlate of technological "innovation". All is in motion, but nothing changes" (DORFMAN, MATTELART, 1975, p. 80)².

Negligenciar deliberadamente ao representar emoções e relacionamentos humanos, minar a memória como uma cadeia inter-relacionada de conhecimento herdado, apresentar a tecnologia isolada do processo produtivo são as receitas da Disney para criar a imobilidade por meio de mudanças mágicas e ilusórias.

Lukács, em $A$ ideologia do Modernismo, critica a abordagem burguês-modernista que tende a enfatizar a técnica formalista e, ao fazê-lo, deixa de lado a questáo da intenção que preside a forma, como demonstra, ao comparar duas amostras de monólogo interior em

\footnotetext{
${ }^{2}$ Esta mudança de cenários sobre um conteúdo idêntico e rígido, a aplicaçáo de uma nova camada de tinta de uma cena para a outra, é o correlato da “inovação” tecnológica. Tudo está em movimento, mas nada muda. (Tradução do autor).
} 
Thomas Mann e James Joyce. Segundo o teórico húngaro, no monólogo de Joyce, "The perpetually oscillating patterns of sense- and memory-data, their powerfully charged -but aimless and directionless- fields of force, give rise to an epic structure which is static, reflecting a belief in the basically static character of events". (LUKÁCS, apud RICHTER, 1998, p. 1218) ${ }^{3}$. Lukács refere-se ao abundante uso de detalhes estranhos, que geralmente são encontrados em todo o trabalho de Joyce, como estáticos, indicando a falta de movimento, ação ou mudança.

De qualquer forma, essa tendência para a imobilidade não é um privilégio dos modernistas, e tanto os abstracionistas quanto os historicistas entendem mal o caráter de um objeto "dado", seja desenraizando-o da experiência social, seja submetendo-o às forças mecânicas do meio ambiente. Devemos considerar que os objetos culturais nunca são "dados”, em vez disso são "constituídos" por meio de relaçôes ambíguas, a ambiguidade entendida aqui não como ausência de um sentido exato, mas no sentido proposto por Merleau-Ponty (2006) como a forma de existência dos objetos da percepção e da cultura não como totalidades fixas, que podem ser separáveis em partes, mas sim como uma totalidade gestáltica, cujas dimensóes simultâneas só podem ser alcançadas por uma racionalidade ampliada.

Devemos entender a ambiguidade, aqui, como uma forma de resistir à tendência de totalizar o conceito do objeto como uma noção passiva e unitária que simplifica e essencializa o que é diferente, ambivalente e plural em um pacote bem suturado, como se fosse apenas uma mercadoria pronta para ser apropriada. Como os conceitos de “incomensurabilidade” e "indeterminação" empregados, respectivamente, por Wai Chee Dimock e Ronald Rudy, a ambiguidade pode funcionar como uma recusa ou uma defesa contra o desejo branco-ocidental europeu de individualizar o outro como contraponto aos seus pressupostos sobre si mesmos.

Embora Zé Carioca tenha antecedentes que até certo ponto lidam com uma forma específica de ser e comportar-se de um grupo delimitado de indivíduos da sociedade

\footnotetext{
${ }^{3}$ Os padrôes perpetuamente oscilantes de dados sensoriais e de memória, seus campos de força poderosamente carregados, mas sem objetivo e sem direção, dão origem a uma estrutura épica que é estática, refletindo a crença no caráter basicamente estático dos eventos (Tradução do autor).
} 
brasileira, especialmente o malandro do Rio de Janeiro dos anos 1930 e 1940, de quem deveria ser representante, ele tem algo diferente: nasceu nos estúdios da Disney e, portanto, é afiliado ao Reino Animal, e pertence a essa cultura construída sobre o mito de uma inocência supostamente universal, além do lugar, além do tempo - e além crítica, conforme escreveram Dorfman e Mattelart.

De qualquer forma, apesar de sua paternidade estrangeira, sua "Mãe Natureza" parece ser brasileira, e para conhecê-lo melhor é necessário rastrear sua genealogia na cultura nativa (não será surpreendente se descobrimos que ele não é o "bom selvagem" que esperamos que ele seja). Além disso, outra grande diferença envolve seu nascimento: o advento da cultura de massa que lhe dotou com o poder mágico da onipresença no jardim da homogeneidade.

\section{O CONTEXTO SÓCIO-HISTÓRICO-CULTURAL DA MALANDRAGEM: A DESVALORIzAÇÃo histórica do TRABALHO E A CONSTRUÇÃo ESTEREOTIPADA DE ZÉ CARIOCA}

Parece que dois fatores maiores, cujas raízes retrocedem ao tempo colonial, devem ser entendidos para explicar uma certa indulgência em relação a um comportamento táo moral e eticamente ambíguo. Uma é a tendência geral, após três séculos de escravidáo, em considerar o trabalho como degradante; o outro é um legado jurídico do período colonial o "jeitinho".

Antes do mais, é importante reconhecer que três séculos de escravidão intensificaram as tendências na cultura brasileira em relação à arrogância, ao egoísmo, ao servilismo e à dependência. Mesmo hoje, mais de um século após a abolição, o preconceito de ex-senhores e ex-escravos em relação a algumas ocupações consideradas manuais é enorme, devido a sua associação com o trabalho escravo. Para o malandro do Rio de Janeiro, a verdadeira contraparte do Zé Carioca da Disney, uma espécie de indivíduo cuja existência foi seriamente comprometida com o advento da industrialização e do capitalismo moderno no Brasil, o trabalho era definitivamente uma palavra excluída de seu vocabulário. 
$\mathrm{Na}$ verdade, para ele, o trabalho não era apenas vergonhoso, mas era "papo de otário", pois ele aprendeu por muitas geraçôes que trabalhar não era nem edificante nem gratificante. Era muito comum nos anos 30, a década de ouro do samba malandro, afirmaçôes como: "eu vejo quem trabalha andar no miserê" e "trabalho não dá camisa a ninguém”. É claro que uma sociedade que impóe essa maneira de considerar o trabalho está predestinada a falhar em um mundo táo econômico como o que surgiu após a Segunda Guerra. Na verdade, nenhuma sociedade preocupada com a justiça social aceitaria essa atitude e muito menos permitiria que ela pudesse ser anexada ao "caráter nacional", como aconteceu no Brasil. É apenas no coração da sociedade colonial, fundada no binômio senhor-escravo, que esse comportamento marginal pode encontrar uma explicação.

Essa dicotomia criou um grupo de pessoas sem classe e sem valor que incluíam negros, índios e brancos livres, bem como as pessoas resultantes da mistura dessas raças: os mestiços. À medida que o período colonial e a economia da escravidão se aproximavam para um fim, esse segmento da população tornou-se mais numeroso, mas ainda não encontrava uma forma de inserção estável na divisão de trabalho exclusivo do sistema da escravidáo, que se baseava em uma agricultura de monocultura direcionada exclusivamente à exportaçáo e dificultava o desenvolvimento de um mercado interno que pudesse criar condiçôes para o surgimento de uma classe média embrionária.

Assim, no decorrer de três séculos de incompetência ou má vontade, para oferecer uma solução para esse problema, o sistema de escravidão criou uma população livre e parasitária que, sem ter conhecido o trabalho árduo, não se proletarizou e ensinou a considerar o trabalho como coisa de escravo. Isso, como já escrevia Monteiro Lobato, em 1911, deu "origem a essa linha divisória, que ainda não se apagou, entre os que trabalham e os que ou promovem o trabalho alheio ou dele vivem, aparasitados". (LOBATO, 1956, p. 147).

Por geraçóes, os membros da classe dominante não precisaram trabalhar, e passaram a considerar isso como atributo de uma raça inferior. Então mantiveram os braços cruzados, deitaram "eternamente em berços esplêndidos" e a indolência tornou-se parte de sua "natureza”. 
Por outro lado, aqueles explorados se tornaram o tipo de indivíduos descartáveis, que não se sentiram comprometidos com os processos essenciais da sociedade em que viviam. Como escreveu Maria Silvia Carvalho Franco, "a agricultura baseada na escravidão simultaneamente abria espaço para a sua existência e os deixava sem razão de ser”. (FRANCO, 1997, p.4)

Segundo observou Lobato, essa depreciação da atividade laboral

Arredou, assim, o brasileiro, das profissôes manuais, da indústria e do comércio, entregues ao elemento alienígena, e marcou-lhe a giz, como campo único para o exercício de suas energias e o só compatível com a sua dignidade, o funcionalismo público, as profissóes liberais, a política e o feitorismo, sob qualquer forma que seja, da massa que lavra a terra. Tudo mais desprezou, como coisas que degradam ou são "impróprias". (LOBATO, 1956, p. 147).

No final do século XIX, simultaneamente à abolição dos escravos, houve a introdução do trabalho assalariado. No entanto, esse período coincide com o grande afluxo de imigrantes europeus que satisfaziam a necessidade de mão-de-obra do capital. Ainda assim, aquele grupo de brasileiros iria continuar a viver à margem do novo sistema. Além disso, a ideia, reforçada por séculos de experiência, de que o trabalho, em vez de dignificar o homem, levava-o à desumanização, acabou por mantê-los afastados das atividades produtivas, que foram capturadas pelo imigrante oportunista e engenhoso.

A diferença talvez fosse que agora eles pudessem se mover dentro de uma sociedade mais flexível e um sistema econômico mais diversificado. Ganhar a vida por um dia, fazendo biscates aqui e ali como forma de viver, tornou-se talvez mais fácil. Por volta de 1874, Herbert H. Smith, um zoólogo americano que visitou o Brasil, escreveu em um artigo para a Scribner's Magazine:

Indolence and pride and sensuality and selfishness, these are the outgrowths of slavery that have enslaved the slavemakers and their children. Do you imagine that they are all rich men's sons, these daintily clad delicate young men on the Ouvidor (a main street in Rio de Janeiro)? The most of them are poor, but they will lead their vegetable lives, God knows how, parasites on their friends, or on the government, 
or on the tailor and grocer, because they will not soil their hands with tools. (SMITH ,1879, p 467). ${ }^{4}$

Essas pessoas eram os "brasileiros" do fin de siécle. Uma classe de gente para a qual trabalhar era depreciativo. Eles se chamavam brasileiros em oposição aos negros e ao imigrante europeu para quem olhavam com desdém.

Essa descrição corresponde ao antepassado imediato de Zé Carioca, de quem ele deve ter herdado a indolência como uma parte da sua "natureza", como era o pensamento comum à abordagem racista típica que dominava a cena intelectual brasileira do final do século XIX e que, intensificada pelas lentes fortes do positivismo, deu origem a postulados como o de que seria impossível existir uma civilização nos trópicos, ou que o mestiço era um homem degradado, sem a inteligência do branco nem o vigor do preto. (VIANNA, 1952; RODRIGUES, 1957).

O mais espantoso é que essas ideias foram compradas por muitos intelectuais brasileiros que, assim como os jovens pobres representados acima pelo viajante norteamericano, também precisavam vestir-se de acordo com a moda europeia. Podemos dizer que essa arrogância, que não é senão um sintoma de imaturidade cultural e uma personalidade insegura (como acontece com frequência em adolescentes), e a aversão ao trabalho são a herança paterna de Zé Carioca.

Por outro lado, podemos dizer que o lado materno de Zé Carioca é o elemento africano (e, em menor grau, o indígena), isto é, a "Mãe Natureza". Sabe-se que, após a abolição, em 1889, os proprietários de escravos, ou porque preferiam substituir seus escravos pelos imigrantes, que eram abundantes e proporcionavam um excesso de trabalho por baixos salários, ou porque simplesmente não tinham motivos econômicos para mantêlos em suas fazendas, despediram-nos. Na verdade, eles foram realmente jogados fora como peças descartáveis de uma engrenagem que não funcionava mais.

\footnotetext{
${ }^{4}$ Indolência, orgulho, sensualidade e egoísmo, estas são as consequências da escravidão que escravizaram os senhores de escravos e seus filhos. Você pensa que todos eles são filhos de homens ricos, esses delicados jovens elegantemente vestidos no Ouvidor (uma rua principal no Rio de Janeiro)? A maioria deles é pobre, mas eles levarão suas vidas vegetando, Deus sabe como, de forma parasitária em seus amigos, ou no governo, ou no alfaiate e no merceeiro, porque eles não irão sujar as mãos com ferramentas. (Tradução do autor).
} 
O governo não forneceu nenhum plano social para incluí-los na nova ordem econômica. A única maneira que eles encontraram foi encurralarem-se nas ruas das grandes cidades como o Rio de Janeiro e se tornarem bêbados, mendigos, e começaram a se instalar nos morros nos arredores das cidades, onde construíram seus "barracos". Nas primeiras décadas do século passado, essa população negra estabeleceu uma série de inter-relaçôes com o elemento urbano, especialmente aqueles que fingiam ser ricos, mas que despencavam na escala social, conforme os imigrantes, por meio do trabalho e da inteligência, foram conquistando os espaços na sociedade.

Devemos observar que no Rio, devido ao relevo, os morros e a cidade ficam face a face, contemplando-se em constante flerte. Essas inter-relaçôes entre o morro e a cidade fizeram do Rio uma das cidades mais miscigenadas do Brasil. Esse cruzamento costumava acontecer entre homens e mulheres de ambas as raças, mas, principalmente, a forma mais aceitável e comum era entre o homem branco e a mulher negra. Portanto, não é difícil imaginar Zé Carioca como um resultado desse conto de fadas dos trópicos, o qual teve como trilha sonora o samba, que se tornou cada vez mais a expressão da cultura popular local. Como Zé Carioca, “o samba nasceu no morro”, dizem as cançôes.

Em uma estrutura econômica táo estritamente dividida, como era a sociedade colonial, aqueles poucos livres que não eram mestres nem escravos não podiam se ajustar a essa ordem e eram relegados a uma vida de insegurança e vicissitudes. Eles eram poucos em número e tinham poucas "escolhas" quanto ao papel a desempenhar nessa sociedade. A alternativa "honesta" seria ficar nos interstícios desses dois mundos sufocantes, ocupando pequenas tarefas aqui e ali, ou viver de favor como um "agregado" em casa de algum senhor benevolente, um tipo de parasita bastante comum na sociedade carioca do século XIX encontramos o representante mais famoso desse espécime na literatura brasileira no personagem servil e lisonjeiro, José Dias, do romance Dom Casmurro, de Machado de Assis.

A alternativa "desonesta" seria tornar-se um malandro ou, no caso feminino, uma prostituta. Como podemos ver, a oposição honestidade/desonestidade, aqui, perde seu significado moral, a tal ponto que seria mais apropriado pensar essa oposição em termos de conformidade/resistência, para podermos compreender a segunda alternativa. 
Antonio Candido (1970), em seu ensaio sobre o herói picaresco na novela Memórias de um Sargento de Milícias, intitulado "Dialética da Malandragem”, deriva a ideia de "malandragem" do que ele chama de "dialética da ordem e da desordem". Rodrigo Suzuki Cintra ao comentar esse binômio dialético proposto por Antonio Candido diz que:

A figura do malandro é a mais adequada a este tipo de organização de mundo em que forças da ordem, como a polícia, por exemplo, concorrem com as forças da desordem. Ele é o tipo que transita entre os dois mundos. Está sempre atuando no limiar, no cinzento, entre o que se pode e o que não se deve fazer. A alternativa lícito/ilícito é perfeitamente relativizada pelo malandro. $\mathrm{O}$ malandro encarna a esperteza popular, sabedoria genérica da sobrevivência em um mundo repleto de obstáculos e iniquidades. (CINTRA, 2015).

Esse movimento dialético supostamente criou uma maneira de ser relativamente livre de repressão moral que, principalmente nos momentos de repressão política pelos quais o Brasil passou periodicamente, foi bem aceito na medida em que funcionou como uma maneira de driblar a censura e ofereceu canais de expressão alternativos para as classes populares. Nas décadas de 1930 e 1970, o povo brasileiro viveu sob o rigor de ditaduras militares que reprimiram ou até suprimiram o direito das classes trabalhadoras à autoorganização e expressão política. Nesses dois períodos, pode-se observar, especialmente em letras de músicas populares, um reforço do malandro como símbolo de resistência contra o opressor.

Os dois compositores que melhor representaram a resistência a esses períodos foram Noel Rosa e Chico Buarque de Hollanda, ambos jovens, brancos, filhos da classe média carioca, que foram seduzidos pelo malandro, pelo samba e pela vida do morro. Quanto ao próprio malandro, seria discutível aplicar a palavra resistência, se entendermos que resistência implica um certo grau de consciência política e engajamento partidário que ele, de fato, não tinha e, portanto, também não haveria como situá-lo nem à esquerda nem à direita do espectro político, uma vez que não há um ideário programático que ele represente, sendo suas açóes orientadas por um individualismo infenso à moralidade comum. 
Essa indefinição possibilitou, por exemplo, que a Disney apresentasse Zé Carioca, no filme Saludo, Amigos, cantando a música "Aquarela do Brasil". Trata-se de uma incoerência grotesca que só pode ser entendida se considerarmos o contexto social e político da época. A partir de 1930, quando Getúlio Vargas assumiu o poder, até o início dos anos 1940, havia no Brasil um regime fascista chamado de "Estado Novo" que, através do DIP (Departamento de Informação e Propaganda), visava sujeitar as massas ao lema fascista da “disciplina e do trabalho" e tentou controlar a representação do heroísmo dentro da vida marginal, de modo que "recomendou" ao malandro regenerar-se, e estimulou os compositores a escrever letras chauvinistas que exaltavam as qualidades das pessoas e a nação.

Na mão oposta, ignorando a "recomendação" oficial, estava Noel Rosa escrevendo sambas que evocavam a pobreza social a que pertencia o "rapaz folgado" e a "moça operária". Noel Rosa recusou a denominação "malandro" por causa de seu significado depreciativo e, contra a proposta oficial de conversão, propôs ao invés de "malandro" ("uma palavra derrotista que só serve pra tirar todo o valor do sambista”) a denominação de "rapaz folgado".

Portanto, o malandro, naquele momento, não estava para cantar sambas do tipo samba-exaltação, do qual "Aquarela do Brasil”, composto por Ary Barroso, é o mais típico representante.

\section{DO MALANDRO DE VERDADE AO MALANDRO OFICIAL, UM MOVIMENTO INVISÍVEL}

No Brasil, especialmente, desde o início do século XIX, quando a nação tornou-se politicamente independente, havia uma preocupação cada vez maior com a formação de uma identidade nacional. Em parte, essa preocupação é justificada devido à vasta área continental do país e, consequentemente, à dificuldade em articular os diferentes polos culturais e políticos que, reunidos sob o regime monárquico e rigidamente centralizado, 
poderiam querer seguir seus próprios caminhos, como, por exemplo, o movimento conhecido como Revolução Farroupilha, no sul do país.

Assim, apesar do abismo social entre as classes e das profundas diferenças culturais regionais, foi criada uma tendência de transformar as diversas manifestaçóes culturais em símbolos de uma coesão nacional. Essa ansiedade na localização de uma identidade nacional ocupou grande parte da produção intelectual brasileira desde então e continua até hoje. Obviamente, esse interesse esteve e está intimamente relacionado com o processo de formação do próprio país - de um lado, havia a necessidade de autoafirmação diante do colonizador estrangeiro; de outro, o desafio de compreender uma diversidade tão incrível no seu interior. Se o contato com o estrangeiro aponta a diferença, então o problema era buscar coerência no quebra-cabeça doméstico.

Consequentemente, no decorrer do tempo, os agentes culturais brasileiros vieram elaborando e redigindo símbolos que poderiam ser representativos do ethos nacional. Obviamente, isso induziu muitas pessoas a representações totalizadoras, como a mistificação do primitivo e do folclórico durante o Modernismo, a crença no mito da Democracia Racial defendida por sociólogos importantes como Darcy Ribeiro, ou o estereótipo mais comum do país e seu povo, incansavelmente representados no tripé samba-carnaval-futebol.

Marilena Chauí descreve esse processo de apropriação de manifestações culturais e sua reelaboração como símbolos nacionais como um "movimento invisível”, que permite a mudança dos "discursos sobre a nação" para o "discurso para a nação" e, finalmente, “discurso da nação". (CHAUÍ, 1986, p. 114). Por um processo de metonímia, o que é particular, regional, temporal é tomado como universal. Esse culto da homogeneização que persiste na cultura brasileira, aliada ao advento do que se denomina indústria cultural ou cultura de massa, foi desastroso para o processo de formação de uma identidade brasileira, na medida em que não se levaram em conta as ambiguidades dos fenômenos culturais.

Essas ambiguidades podem variar de um extremo de positividade a um extremo de negatividade, de acordo com as circunstâncias específicas de uma determinada sociedade em um determinado momento histórico, que é operado em um nível simbólico capaz de orientar comportamentos e ser um instrumento de coesão entre os indivíduos e a sociedade. 
Esse "movimento invisível" pode ser percebido na transformação de Zé Carioca, desde os primeiros desenhos animados lançados nos anos 1940 aos quadrinhos, que foram muito populares nos anos 1970: dois períodos de história brasileira marcados por algumas particularidades. Em ambos os períodos, havia uma forte preocupação da parte dos EUA para evitar que o Brasil fosse seduzido por doutrinas anticapitalistas, primeiro a ameaça do fascismo e depois o perigo do socialismo.

Em ambos os períodos, era necessário que os EUA apresentassem prova de "boa vontade" em relação ao país sul-americano, e a prova era abundante: primeiro, durante a ditadura de Vargas, a nota principal era a amizade mútua e as usinas metalúrgicas. Enquanto os tecnocratas governamentais cuidavam da metalurgia, Disney e Hollywood forneceram evidências de uma simpatia irresistível de ambos os lados. A personalidade de Zé Carioca nos desenhos foi uma reminiscência da camaradagem típica dos brasileiros nativos, um protótipo do "homem cordial", tanto expansivo quanto receptivo, conforme mostrou Sergio Buarque de Hollanda (2006). Ao mesmo tempo, Carmem Miranda estava remexendo seus quadris e cantando sambas, vestindo trajes adornados com bananas, laranjas, abacaxis.

Mas, na década de 1970, essa relação de "boa vizinhança" foi degradada, porque o capitalismo não cumpriu as promessas de prosperidade e, em vez disso, concentrou a riqueza nacional.

Assim, é possível ver aquela grotesca incoerência cometida pela Disney, no filme Saludo Amigos, ao colocar o papagaio malandro cantando "Aquarela do Brasil", como muito conveniente. Lá, podemos ver Zé Carioca desfilar vestido exatamente segundo a "moda da malandragem" - terno descolado, chapéu Panamá, um guarda-chuva, fumando um charuto Havana - uma descrição perfeita da figura hedonista que realmente corresponde ao estereótipo. A História, contudo, não está lá.

Despojado de todas as suas ambiguidades, Zé Carioca torna-se Joe Carioca, e em vez de cantar um "samba-malandro" de Wilson Batista, ou mesmo um "samba-rapaz folgado" de Noel Rosa, canta "Aquarela do Brasil". Aquele era um momento em que a malandragem se confrontava com a política (e a polícia) do governo Vargas, que tinha 
como objetivo a regeneração do malandro (MATOS, 1982). A Disney, com seus poderes mágicos, conseguiu fazer o que a ditadura de Vargas estava tentando sem sucesso: converter o malandro - Zé Carioca é uma tentativa de mostrar que é possível ser um "bom malandro", pelo menos no Reino Animal.

Essa tentativa de domesticar e incorporar ao personagem nacional o que é uma espécie de atitude dionisíaca reforçada pelo samba, o carnaval, a vadiagem, a capoeira, o futebol, etc, pode ter consequências deletérias no processo de autorreconhecimento de uma nação. Em outras palavras, tornar oficial e autorizar algo que não é essencial ao "caráter brasileiro", como se poderia supor, mas que, na sua origem e na sua formação, é definido marginalmente como traço da classe hegemônica, pode ter efeitos desastrosos no processo de autorrepresentação do "povo brasileiro".

Digo desastrosos porque, além da ansiedade dos brasileiros por uma homogeneização da raça e da cultura numa busca desesperada de uma identidade nacional, no Brasil, os serviços de telecomunicações são concedidos pelo Estado a empresas privadas com base em concessóes políticas, de modo que permaneçam comprometidos mediante um conluio em que é difícil distinguir o que é ideologia e propaganda do estado do que são interesses privados dos grupos capitalistas.

É interessante observar como o mesmo personagem, o malandro, durante a ditadura militar dos anos 1970, foi representado de maneiras tâo diferentes. Na MPB (Música Popular Brasileira), especialmente nas músicas de Chico Buarque, podemos encontrar o discurso da malandragem sendo usado para funcionar como uma linguagem codificada para driblar os censores, enquanto nas HQs da Disney a mensagem reforçava a atitude irresponsável de segmentos da elite privada e governamental brasileira (no Brasil nem sempre é fácil diferenciar privado de público) que estavam tomando empréstimos de governos e instituiçóes financeiras internacionais para fins que nunca foram bem claros.

Nas HQs, o malandro se assemelhava mais a um alpinista social, um papagaio pobre tentando obter sua parte da alta sociedade, às vezes agitado, ganhando dinheiro ao fazer coisas que não são exatamente legais ou éticas. Esse Zé Carioca também devia dinheiro a quase todos. Havia, inclusive, uma associação chamada ANACOZECA. - Associação 
Nacional dos Cobradores do Zé Carioca, da qual ele estava sempre fugindo e que era um dispositivo recorrente da narrativa.

Quaisquer semelhanças com o Brasil dos anos 1980 não são meras coincidências. O Zé Carioca da Disney dos anos setenta é uma representação clara da disposição mental que prevalecia nas classes empresariais e políticas nacionais, que visavam tirar proveitos das circunstâncias, não se importando com os danos que essa atitude traria para toda a sociedade, demonstrando um egoísmo que só pode ser possível em uma situação de uma brutal alienação social e asfixia política. Esse comportamento ficou amplamente conhecido como a "lei de Gerson". Gerson era o capitão do time brasileiro que ganhou a Copa do Mundo em 1970 e apareceu em um anúncio publicitário de uma marca de cigarros na TV de cigarros, veiculado no ano de 1976, propagando ao país um slogan que dizia: "Eu gosto de levar vantagem em tudo, certo? Leve vantagem você também”. Segundo Maria Izilda Matos, "para o período era um jargão superdifundido. A propaganda captou um elemento de identificação que estava no imaginário popular”. (MATOS, 1999).

\section{CONSIDERAÇÕES FINAIS}

Portanto, sob a força de um aparato de comunicação concentrado na mão de alguns poucos agentes, o que deveria ser um tipo carregado de ambiguidades, uma construção histórica datada, é imposto, a partir de alguns traços periféricos, como identificador do caráter nacional. Isso, em um momento no qual o malandro histórico já havia praticamente desaparecido, como sugere a canção "Homenagem ao malandro", de Chico Buarque de Hollanda, que aparece em 1979 no álbum Ópera do Malandro:

Eu fui fazer

um samba em homenagem

à nata da malandragem

que conheço de outros carnavais

Eu fui à Lapa e perdi a viagem

que aquela tal malandragem

não existe mais. (HOLLANDA, 1979) 
No lugar do malandro, como figura histórica do Rio de Janeiro, frequentador dos bares da Lapa, podemos observar que as mudanças econômicas simplesmente extinguiram a malandragem tradicional e deram lugar a um novo malandro, não mais marginalizado, e sim, regularizado, profissionalizado, de acordo com os ditames da moderna tecnocracia brasileira, como ficou bem textualizado na mesma canção de Chico Buarque.

\author{
Agora já não é normal \\ O que dá de malandro \\ regular, profissional \\ Malandro com aparato \\ de malandro oficial \\ Malandro candidato \\ a malandro federal \\ Malandro com retrato \\ $\mathrm{Na}$ coluna social \\ Malandro com contrato \\ com gravata e capital \\ que nunca se dá mal. (HOLLANDA, 1979)
}

O que restou do malandro foi a sua proletarizaçáo completa, tendo se convertido em assalariado, vivendo precariamente nos subúrbios, como a maioria dos brasileiros, inclusive aqueles metidos a ricos que, em fins do século XIX, haviam emprestado os traços hedonistas de que a Disney se serviu para compor o seu personagem. Em sua busca pelo malandro, é assim que o eu-lírico da canção de Chico Buarque o encontra no arremate da canção:

Mas o malandro pra valer

- Não espalha

Aposentou a navalha

Tem mulher e filho e tralha e tal

Dizem as más línguas que ele até trabalha

Mora lá longe e chacoalha

Num trem da Central. (HOLLANDA, 1979) 


\section{REFERÊNCIAS}

CANDIDO, Antonio. Dialética da malandragem. Revista do Instituto de Estudos Brasileiros da USP, n. 8, 1970.

CAVALCANTE, Rodrigo. (2005). A Cara do Brasileiro. In: Super Interessante, São Paulo, n. 217, p.68-74, set. 2005.

CHAUÍ, Marilena. Conformismo e Resistência. São Paulo, Ed. Brasiliense, 1986.

CINTRA, Rodrigo Suzuki. Ordem e desordem na crítica brasileira: sobre um ensaio de Antonio Candido. Revista Carta Capital, Sáo Paulo, 2015. Disponível em: http://justificando.cartacapital.com.br/2015/03/09/ordem-e-desordem-na-critica-brasileirasobre-um-ensaio-de-antonio-candido/. Acesso em: 01 out. 2017.

DIMOCK, Wai Chee. Residues of Justice: Literature, Law, Philosophy. Berkeley: University of California Press, 1996.

DORFMAN, Ariel. MATTELART, Armand. How to Read Donald Duck: Imperialist Ideology in the Disney Comic. London: I.G. Editions, 1975.

FRANCO, Maria Sylvia de Carvalho. Homens livres na ordem escravocrata. São Paulo: Fundação Editora da UNIESP, 1997.

HOLLANDA, Chico Buarque de. Ópera do malandro. São Paulo, Cultura, 1979.

HOLlANDA. Sérgio Buarque de. Raizes do Brasil. São Paulo: Companhia das Letras, 1996.

LOBATO, Monteiro. A doutorice”. In: Mundo da Lua e Miscelânea. São Paulo: Brasiliense, 1956.

MATOS, Cláudia. Acertei no Milhar: Samba e malandragem na Era Vargas. Rio de Janeiro: Paz e Terra, 1982.

MATOS, Maria Izilda. Lei de Gerson: o país passou por várias crises de identidade neste século. In: IstoÉ, São Paulo, 1999. Disponivel em: https://istoe.com.br/27207_LEI+ DE+GERSON+/. Acesso em 03 out. 2017.

MERLEAU-PONTY, M. As Aventuras da Dialética. São Paulo: Martins Fontes, 2006.

RICHTER, D. H. The Critical Tradition: Classic Texts and Contemporary Trends. Boston: Bedford Books, 1998.

RODRIGUES, Raimundo Nina. As Raças Humanas e a Responsabilidade Penal no Brasil. Salvador: Livraria Progresso, 1957. 
SMITH, Herbert H. Brazil, the Amazons and the coast. New York: Charles Scribner's Sons, 1879. Disponível em: https://archive.org/stream/brazilamazonscoa00smit\#page/n1/ mode/2up. Acesso em: 05 out. 2017.

VIANNA, Oliveira (1952). Populaçôes Meridionais do Brasil. RJ, José Olympio Editora. 